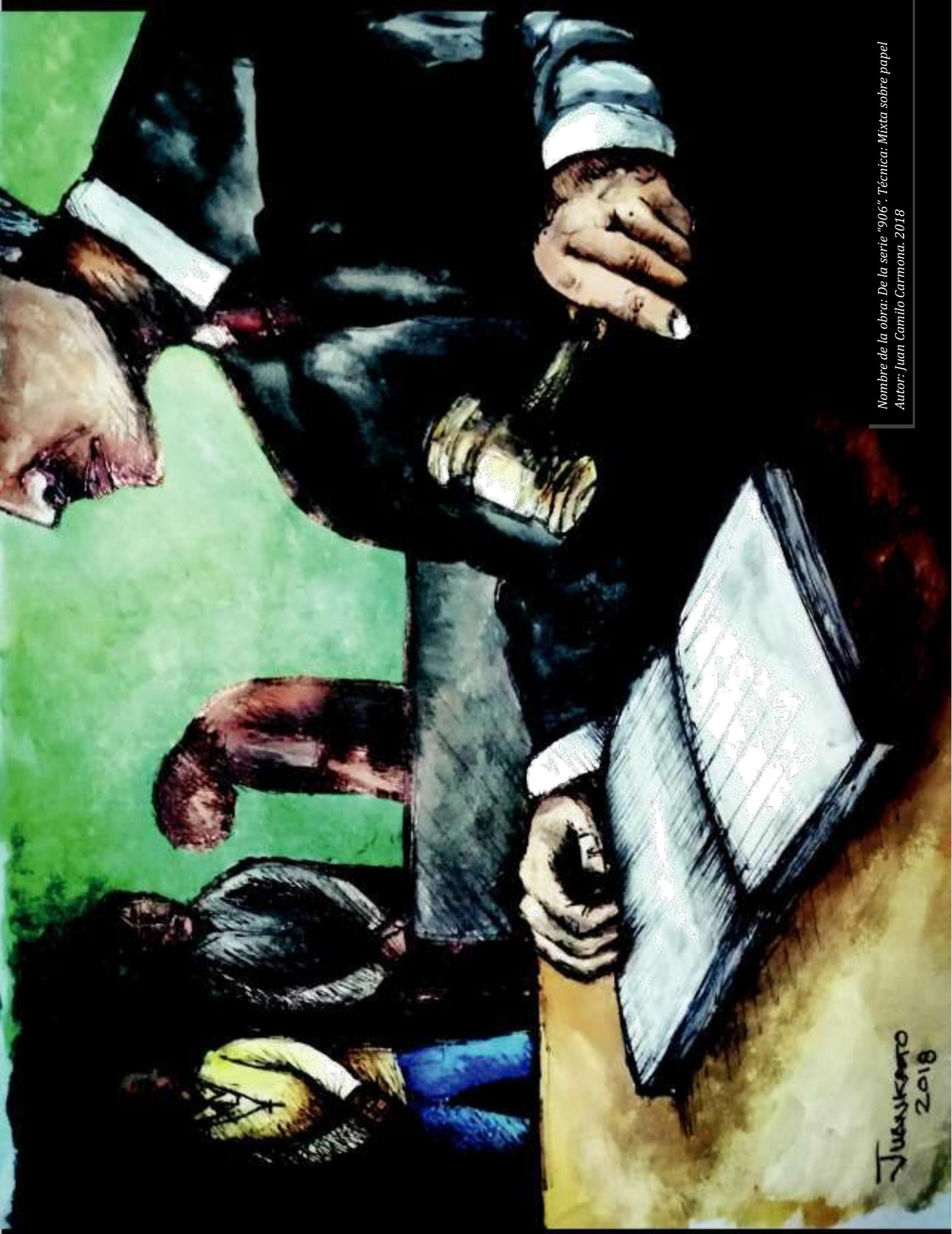




\title{
(Re) pensar el federalismo fiscal: un estudio de las facultades del Congreso de la Nación Argentina para eximir el pago de tributos*
}

\author{
Luciano Rezzoagli**
}

\section{Resumen}

El objetivo central de este artículo es determinar la existencia o inexistencia de un verdadero poder autónomo de eximir del pago de tributos a los sujetos beneficiados que disponga el Congreso de la Nación Argentina, respecto a cualquier tributo nacional o subnacional por consideraciones de progreso y desarrollo del país, en función de la disposición constitucional que establece a este respecto el artículo 75 inciso 18. En este estudio científico de metodología cualitativa, lógico - jurídico y descriptivo - analítico, se replantean las bases mismas del federalismo fiscal y fundamentalmente del poder tributario, otorgando luz a un tema escasamente tratado, pues la construcción doctrinal (ya antigua y generalmente aceptada) no establece bases jurídicas sólidas y la jurisprudencia de la Corte Suprema de la Nación Argentina es ambigua, provocando que la falta de coherencia discursiva entre la teoria y la praxis genere confusión e inequidad en el ejercicio del poder tributario de imposición.

Palabras clave: poder tributario; federalismo fiscal; impuestos; incentivos fiscales; equidad.

\section{(Re) thinking fiscal federalism: A study of the faculties of the Argentinian Congress to exempt the payment of taxes}

\begin{abstract}
The central objective of this article is to determine the existence or nonexistence of a true autonomous power to exempt from the payment of taxes to the beneficiaries provided by the Argentine National Congress, with respect to any national or subnational tax for considerations of progress and development of the country, in accordance with the constitutional provision that establishes in this respect article 75 paragraph 18 . In this scientific study of qualitative, logical - juridical and descriptive - analytical methodology, the very foundations of fiscal federalism and fundamentally of tributary power are reconsidered, giving light to a scarcely treated topic, since the doctrinal (already ancient) and jurisprudential construction is ambiguous and the lack of discursive coherence between theory and practice generates confusion and inequity in the exercise of the taxing power of imposition.
\end{abstract}

Keywords: tax power; fiscal federalism; taxes; fiscal incentives; equity.

\section{(Re) pensar o federalismo fiscal: um estudo das faculdades do congresso da nação argentina para isentar do pagamento de tributos}

\section{Resumo}

O objetivo central deste artigo é determinar a existência ou inexistência de um verdadeiro poder autônomo de isentar do pagamento de tributos aos indivíduos beneficiados que dispuser o Congresso da Nação Argentina, sobre qualquer tributo nacional ou subnacional por consideraçóes de progresso e desenvolvimento do país, em função da disposição constitucional que estabelece a este propósito o artigo 75 alínea 18. Neste estudo científico de metodologia qualitativa, lógico - jurídico e descritivo - analítico, reformulam-se as bases do federalismo fiscal e fundamentalmente do poder tributário, esclarecendo um assunto pouco tratado, pois a construção doutrinal Gá antiga geralmente aceita) não estabelece bases jurídicas sólidas e a jurisprudência do Supremo Tribunal da Nação Argentina é ambígua, fazendo com que a falta de coerência discursiva entre a teoria e a práxis gere uma confusão e inequidade no exercício do poder tributário de imposição.

Palavras-chave: poder tributário; federalismo fiscal; impostos; incentivos fiscais; equidade.

\footnotetext{
* Artículo de reflexión. Es el resultado del proyecto desarrollado en el marco de las investigaciones sobre Federalismo Fiscal y Asimetrías Regionales llevadasa caboy financiadas por Conicet-UNL,lugarde trabajo:IHUCSO LITORAL, Candido Pujato 2751. (C. P.3000) Santa Fe. Argentina | Tel (54) 0342 - 4571200.

** Investigador Adjunto de Conicet y profesor titular de la cátedra de Derecho Tributario, Financiero y Aduanero de la Facultad de Ciencias Jurídicas y Sociales de la Universidad Nacional del Litoral (FCJS - UNL). Abogado de la Universidad Católica de Santa Fe. Magíster y Doctor en Derecho Tributario de la Universidad de Salamanca, España. Posdoctorado en Federalismo Fiscal por el Conicet - UNL. Profesor titular de Derecho Financiero, Tributario y Aduanero de la carrera de Abogacía en FCJS - Universidad Nacional de Litoral, Santa Fe, Argentina. Profesor de posgrado en Universidades de Argentina, Colombia, Ecuador, México y Nicaragua, Correo electrónico: Irezzoagli@hotmail.com. ORCID: 0000-0002$7400-4042$
}

Cómo citar este artículo: Rezzoagli, L. (2019). (Re) pensar el federalismo fiscal: un estudio de las facultades del Congreso de la Nación Argentina para exi mir el pago de tributos. Estudios de Derecho, 76 (167), pp-pp. 65- 


\section{(Re) pensar el federalismo fiscal: un estudio de las facultades del Congreso de la Nación Argentina para eximir el pago de tributos}

\section{Introducción}

Los indicadores más relevantes que permiten medir el desarrollo de un sistema federal son, entre otros: la graduación de la autonomía política de los gobiernos existentes (nacional - subnacionales), la autonomía normativa y la autonomía económico-financiera de estos, como así también la constatación (evaluación) de una realización efectiva del diseño constitucional normativo y la práctica efectiva del modelo federal a través de las herramientas de concertación y las políticas públicas implementadas al efecto.

Respecto de este último elemento, para Domínguez (2015), "es posible encontrarse con diseños muy precisos y prácticas anómicas irreversibles, o bien, con diseños más imprecisos que posibilitan la degradación de legítimos objetivos propuestos en torno al fortalecimiento del sistema federal" (p. 94). La "federación unitaria" o "unidad federativa" propuesta por Juan Bautista Alberdi en las Bases y puntos de partida para la organización política de la República de Argentina, tenía como plataforma la república representativa y federal con un régimen presidencial vigorizado y predominante. La República Federal Argentina de la Constitución de 1853 siguió en gran medida la propuesta de Alberdi, aunque con importantes modificaciones en lo atinente a la conformación del Poder Ejecutivo y la estructuración del orden económico-financiero (Domínguez, 2015).

La reforma constitucional de 1994 tuvo como objeto fortalecer el régimen federal (punto A del temario libre habilitado por la ley 24.309). Muchos de los objetivos que persigue el federalismo argentino luego de la reforma de 1994 se encuentran presentes en el art. 75 incisos 18 (anterior 67 inc. 16) y la novedad del inciso 19 (relativo a la igualdad de oportunidades regionales), cuando se establece como una atribución - obligación del Congreso a proveer al adelanto y bienestar de todas las provincias, así como también el crecimiento armónico de la Nación promoviendo políticas diferenciadas y solidarias que tiendan a equilibrar el desigual desarrollo relativo de provincias y regiones. 
Estos objetivos se enlazan directamente con el sistema de derechos del modelo constitucional y convencional argentino (conformado por los derechos fundamentales y los derechos humanos) y su efectiva concretización. Sin embargo, en materia fiscal, como analizaremos pormenorizadamente en este artículo científico, dichos objetivos plantean dudas razonables en cuanto a su forma de cumplimiento y efectiva concretización. El artículo 75, inciso $18^{1}$ de la Constitución de la Nación Argentina establece: (es facultad del Congreso de la Nación)

Proveer lo conducente a la prosperidad del país, al adelanto y bienestar de todas las provincias, y al progreso de la ilustración, dictando planes de instrucción general y universitaria, y promoviendo la industria, la inmigración, la construcción de ferrocarriles y canales navegables, la colonización de tierras de propiedad nacional, la introducción y establecimiento de nuevas industrias, la importación de capitales extranjeros y la exploración de ríos interiores, por leyes protectoras de estos fines y por concesiones temporales de privilegios y recompensas de estímulo.

Como se puede observar de la letra de este inciso, el constitucionalista nos da una lista de prioridades de dudosa justificación técnica para conceder exenciones impositivas en aras del progreso nacional, sin embargo, tal como señala Bidart Campos (2000), dicha cláusula "es de una amplitud manifiesta y engloba en su enunciado una temática que, sin carácter taxativo, equivale a los contenidos del Bien Común y de lo que hoy se denomina desarrollo" (p. 121). Ahora bien, también podemos apreciar como la recepción de los elementos minorativos de la obligación tributaria encuentran justificación en la frase “... concesiones temporales de privilegios y recompensas de estímulo"2. Una visión apresurada de este precepto permite pensar que pueden establecerse toda clase de minoraciones según la conveniencia y necesidad del país, cosa que merece una cuidadosa revisión y análisis.

Como señala bien Bulit Goñi (1991), en el artículo 75 constitucional, el inc. 18 actúa en forma sistemática con los incs. 13 (posibilita a las provincias y municipios gravar las actividades comerciales interjurisdiccionales, inclusive el transporte de personas y cosas, en tanto el gravamen local no implique una aduana interior, no se erija en un derecho de tránsito, no se aplique por el mero paso, entrada o salida de los bienes o personas, no tuerza las corrientes naturales de circulación y transporte, no discrimine según el origen o destino de ellos y no opere como un

1 El precepto de este artículo se encuentra incorporado en la Constitución Nacional desde la reforma del año 1994. Anteriormente y en los mismos términos se encontraba establecido en el artículo 67, inciso 16, de nuestra Carta Magna.

2 Para Luqui (1993), "la prosperidad del país, el bienestar de todas las provincias y el progreso de la ilustración, han de realizarse mediante medios que el mismo inciso enumera, es decir, promoviendo la industria, la inmigración, la construcción de ferrocarriles, canales navegables, etc.; y los recursos para hacer efectivos esos medios no son otros que las concesiones temporales de privilegios y recompensas de estímulo" (pp. 302 y 303). 
instrumento de protección de la economía provincial, en detrimento de la de otras provincias o del extranjero) y 30 , (autoriza a las provincias y municipios a gravar los actos y actividades desarrollados en lugares o establecimientos de utilidad nacional, en tanto no interfieran con el cumplimiento de los fines allí perseguidos), en cuanto la Nación puede eximir de gravámenes locales a las actividades interjurisdiccionales o realizadas en los establecimientos de utilidad nacional, o bien consentir su aplicación. Mas esta facultad no es ilimitada ni podría ejercerse caprichosamente en desmedro de las atribuciones provinciales o municipales. Es decir, que siempre necesitará de una causa admisible de justificación, tanto para vedar la imposición como para admitirla (en los supuestos de concurrencia con los incisos 13 y 30), ya que de lo contrario, estará expuesta a los reclamos de las autoridades locales o de los particulares, respectivamente. De todas maneras, una vez ejercida la potestad del inciso 18 , como los jueces no pueden investigar sobre la oportunidad, mérito o conveniencia de la medida, solo les queda el angosto resquicio de la violación de la razonabilidad, conforme con la interpretación dada al artículo 28 constitucional (Naveira de Casanova, 2007).

El artículo 125 constitucional, primera parte, también reconoce similares facultades a las provincias cuando establece:

promover su industria, la inmigración, la construcción de ferrocarriles y canales navegables, la colonización de tierras de propiedad provincial, la introducción y establecimiento de nuevas industrias, la importación de capitales extranjeros y la exploración de sus ríos, por leyes protectoras de estos fines, y con sus recursos propios.

Siguiendo la doctrina especializada, este artículo en cuestión se enmarca dentro de la doctrina de inmunidad de los instrumentos de gobierno. Dicha inmunidad "corresponde a un tipo de exención, pero cuyo origen es la Constitución Nacional y no una simple ley, por lo que solo habrá inmunidad tributaria, exclusivamente, cuando una norma o principio constitucional lo establezca literalmente" (Uriburu, 2017, p.2).

Ahora bien, la inmunidad puede llegar a ser vista también como un supuesto de no sujeción, cuestión que pertenece al plano del debate académico, en cuanto ésta haga referencia a supuestos en que se carezca de una subyacente capacidad contributiva gravable en ciertas actuaciones (del Estado o de otros) ${ }^{3}$. En este

3 Creemos que, justamente, los problemas se presentan o se manifiestan para el intérprete cuando se pretende delimitar conceptualmente institutos tan íntimamente relacionados entre sí como la exención y la no sujeción. Ello se debe a que muchas veces la frontera de diferenciación entre dichos conceptos es difícil de precisar, sobre todo si se atiende a que es el legislador quien regulando de una u otra manera, va a determinar cuando una conducta o una situación estará sujeta pero exenta, y cuando otra conducta, o quizás la misma, estará no sujeta a un determinado impuesto. La prueba de estas afirmaciones la podremos encontrar al analizar el empleo que de estas figuras realiza el propio legislador terminológicamente, ya que muchas veces se denomina exención lo que en realidad es una norma de no 
sentido, no puede haber hecho imponible si no existe capacidad contributiva en el sujeto pasivo del tributo (Uriburu, 2017). De esta manera, al no haber riqueza en el Estado, ya que todos sus recursos están destinados a la satisfacción de fines públicos, no puede existir tributo en las actividades económicas del Estado ${ }^{4}$.

\title{
A este respecto ya se manifestaba tiempo atrás Berliri, afirmando que:
}

\begin{abstract}
tanto la falta de legitimación (normas de no sujeción) como la exención determinan la inaplicabilidad del tributo, sin embargo, no deben confundirse ya que son claramente diferenciadas; se observa en el primer caso que la obligación tributaria no surge porque no se ha verificado el presupuesto de hecho previsto por el legislador, mientras que en el segundo, ésta no surge porque al verificarse el presupuesto
\end{abstract}

sujeción o viceversa (basta con mirar el artículo 20 de la Ley de Impuesto a las Ganancias para encontrar un abanico de situaciones materiales diversas enmarcadas literalmente bajo el rótulo de exenciones). Por ello, sostenemos que no basta con afirmar que los preceptos de no sujeción constituyen supuestos didácticos de los que se puede prescindir, ya que la finalidad de éstos coincide con la de las exenciones, es decir, pretenden que algunos sujetos o actividades no tributen para ciertos casos determinados (aunque las consecuencias jurídicas sean muy diferentes, ya que en las exenciones se neutraliza la obligación principal o material de pago pero son exigibles las demás obligaciones formales por haberse devengado el hecho imponible), y si no se precisa con exactitud la naturaleza de las mismas y su modus operandi, no habría un criterio valido de distinción que permita diferenciar unas de otras.

Las normas de no sujeción no pueden de igual manera instaurarse o suprimirse al arbitrio del legislador sin justificación alguna, sino que cumplen una función específica querida por dicho legislador tributario siguiendo un criterio de justicia y eficacia. Así, pues, estos supuestos constituyen auténticas normas jurídicas que la doctrina italiana ha llamado "a fattispecie exclusiva", es decir, constituyen las llamadas normas jurídicas incompletas, ya que encuentran justificación y razón de ser en otra de carácter más general. En el caso de la no sujeción, estas normas se complementan con las que establecen el presupuesto fáctico o hecho imponible de una determinada obligación tributaria, actuando o cumpliendo la función de delimitar, en el mismo presupuesto de hecho, los límites de éste en forma negativa, es decir, explicitando en la norma aquellos supuestos o elementos que quedan fuera del ámbito de la tributación. Por consiguiente, rechazamos la concepción de que esta figura constituye presupuestos didácticos sin contenido jurídico, pues no representan de manera fiel la verdadera naturaleza de esta figura.

Por todo lo expuesto, entendemos que constituyen supuestos de No Sujeción aquellas normas jurídicas aclaratorias que, actuando desde fuera del hecho imponible, lo delimitan por vía negativa.

4 Consideramos adecuado y relevante citar textualmente la opinión de Naveira de Casanova (2007) en lo relativo a la doctrina de la inmunidad de los instrumentos de gobierno cuando afirma que es el principio de Capacidad Contributiva el que aporta luz y claridad a esta temática, puesto que: "Me parece claro, dentro de este orden de ideas, que el Estado carece a todas luces de capacidad contributiva en ese sentido absoluto o, mejor, en el sentido de causa de las obligaciones de naturaleza tributaria. Ciertamente, no posee la riqueza como los particulares (sean personas físicas o jurídicas), puesto que todo el patrimonio estatal está destinado -afectado- a cumplir con su cometido constitucionalmente expresado: el afianzamiento de la Justicia en sentido general y abarcador de todos aquellos fines loables que atribuyamos al Estado, desde cualquier perspectiva política democrática. En términos más sencillos y directos, se puede expresar que al Estado, con independencia de cual fuere su situación patrimonial o financiera concreta en un momento dado, nunca le "sobra" la riqueza que posee, ni siquiera una parte, puesto que toda ella, sin importar su magnitud ni su composición, se encuentra destinada al cumplimiento de su objetivo. No hay posibilidad de considerar un remanente más allá de ciertas necesidades consideradas básicas, elementales o imprescindibles, como el que señalé en el caso de los particulares.

Todo valor que ingresa en las arcas estatales -por vía tributaria o no tributaria- está, obligatoriamente, destinado al gasto público -actual o futuro-. El gasto público, por discutible que sea tal o cual empleo del mismo en cada caso concreto es, en sí, esencialmente diferente del gasto que pueda realizar un particular. El Estado se encuentra autorizado u obligado -según el caso- a gastar. Y en general, antes o después, deberá gastar o utilizar (invertir) todo lo que a su tesoro ingresa. No hay posibilidad para una utilización privada de los bienes públicos en sentido lato" (p. 15). 
de hecho se ha producido otra circunstancia que neutraliza la eficacia del mismo. Entre estas dos situaciones existe una antítesis, ya que en la falta de legitimación se está en presencia de una situación a la que resta algo para ser el presupuesto de hecho previsto por el legislador como idóneo para determinar el nacimiento de una obligación tributaria; mientras en la exención tributaria se está en presencia de una situación que representa algo más del presupuesto de hecho (1971, p. 372).

Evidentemente el artículo 75 inciso 18 constitucional al referirse en su parte final a concesiones temporales de privilegios y recompensas de estímulo, establece instrumentos de inmunidad de gobierno, justamente porque las exenciones y/ normas de no sujeción que contempla tienen jerarquía máxima y no se delimitan en una ley. Esto genera un supuesto especial que nos plantea un ámbito de desarrollo doctrinal interesante a tratar en este escrito, puesto que las exenciones y los supuestos de no sujeción generalmente se encuentran enmarcados dentro de la ley del impuesto al que afectan, lo que no deja mayores dudas de su alcance y vinculación, y en las leyes o decretos leyes promocionales (beneficios tributarios o fiscales), se establecen los impuestos a los que serán afectados, puesto que, sin excepción, si son leyes promocionales provinciales afectan a tributos provinciales establecidos literalmente o sin son leyes promocionales nacionales afectan, de la misma manera, impuestos de administración nacional.

Sin embargo, tratándose de instrumentos de inmunidad de los actos de gobierno (exenciones y/o supuestos de no sujeción con jerarquía constitucional) ya no es claro su ámbito de afectación y si puede o no corresponderse a un auténtico poder autónomo de exoneración distinto al poder de exigir tributos o de imposición, puesto que, como se analizará en este trabajo, dicha facultad exonerativa del Congreso de la Nación fue interpretada por la Corte y la doctrina, con carácter general, como situación excepcional y por tiempo limitado, y en ponderación con el criterio o principio de Razonabilidad.

Por lo expuesto, las preguntas centrales que guían a esta investigación son las siguientes:

¿El artículo 75 inciso 18 de la Constitución Nacional estipula el ejercicio de un poder autónomo, independiente al propio poder impositivo? ¿Se trata formal y materialmente de dos poderes distintos? ¿Qué efectos e implicancias estructurales tiene esta disposición constitucional en el modelo de organización federal, tanto teóricas como prácticas?

Para comprender claramente la articulación de instrumentos utilizados en un supuesto "poder" de eximir de tributos a cualificados sujetos o actividades escogidas por el legislador nacional, de forma autónoma, es importante definir y comprender como actúan las minoraciones fiscales dentro de la propia configura- 
ción del tributo; para ello escogimos representar el análisis de estas herramientas con las figuras de Exención y la de Beneficios Fiscales.

\section{Análisis de las exenciones y beneficios tributarios}

Desde antaño el concepto de exención evocó la idea de privilegio. En la época anterior al Estado de Derecho, en el mundo de la tributación, gozaban precisamente de exención de tributos los nobles y el clero, lo cual constituía un tratamiento de favor de difícil justificación jurídica. Las revoluciones de finales del siglo XVIII incluyeron entre sus conquistas la abolición de tales privilegios y la igualdad de los ciudadanos ante la ley. No es coincidencia que la vigente Constitución de los Estados Unidos Mexicanos, de 1917, imponga, en su artículo 28, una prohibición de monopolios y estancos de cualquier clase, así como una prohibición de exención de impuestos. De igual forma, era ilustrativo el artículo CXVIII de la Constitución Española de 1808, en el que se establecía que "todos los privilegios que actualmente existen concedidos a cuerpos o a particulares quedan suprimidos", pero, sobre todo, el artículo 339 de la Constitución Liberal promulgada en Cádiz, el 19 de marzo de 1812, que rezaba: "Las contribuciones se repartirán entre todos los españoles con proporción a sus facultades, sin exención ni privilegio alguno”.

La Constitución de la Nación Argentina no contempla entre sus prohibiciones el término privilegio, sin embargo, de su artículo 16 puede extraerse, sobre todo de su parte final, dicha prohibición por simple razonamiento lógico. Así este artículo preceptúa: "La Nación Argentina no admite prerrogativas de sangre, ni de nacimiento: no hay en ella fueros personales ni títulos de nobleza. Todos los habitantes son iguales ante la Ley, y admisibles en los empleos sin otra condición que la idoneidad. La igualdad es la base del impuesto y de las cargas públicas". De esta manera el Estado de Derecho excluye la existencia de privilegios de clase alguna y proscribe cualquier discriminación de carácter tributario.

En concordancia con esta afirmación, la Constitución Española de 1978, al igual que otras Constituciones democráticas, proclama que "los españoles son iguales ante la Ley, sin que pueda prevalecer discriminación alguna por razón de nacimiento, raza, sexo, religión, opinión, o cualquier otra condición o circunstancia personal o social". En el ámbito tributario, este artículo se complementa con el 31 CE donde el principio de igualdad está explícitamente incluido entre los principios rectores del sistema fiscal. Desde esta perspectiva jurídica comenzó a considerarse la exención como un instituto jurídico merecedor de análisis en el campo del Derecho, siendo objeto de estudio de los más prestigiosos doctrinarios en la materia. Debido a esto, en la actualidad, han perdido vigor las palabras de Berliri, quien calificaba la exención como "campo inexplorado del derecho tributario" (1971, de p. 328), aunque todavía resulta de difícil trayecto. Hoy es pacífica la doctrina 
que considera la exención como "instituto jurídico" y no como una manifestación arbitraria del poder político, y, por tanto, como una materia reglada sometida al imperio de la Constitución y de la Ley Ordinaria. Sin embargo, ha sido Sainz De Bujanda (1963) quien ha advertido sobre "el riesgo de un empleo abusivo de la exención con fines extrafiscales" (p. 431), juzgando que éstas han de restringirse paulatinamente. Como puede manifestarse en la legislación tributaria, la adopción de medidas que responden a fines extrafiscales, es decir, que exceden del ámbito normal del tributo, suelen confundirse por su estructura y modus operandi con las exenciones y demás minoraciones tributarias, por lo que constituye un objetivo de esta obra, y en especial de este capítulo, el esclarecimiento y definición de estas técnicas y su diferenciación de las demás figuras que responden de manera directa a la realización de fines estrictamente tributarios.

\section{La Exención Tributaria}

\section{Como Presupuesto Excepcional}

Con el término exención se define, para algunos autores, el efecto de ciertos supuestos incluidos en el ámbito del hecho imponible cuya realización, pese a ello, no da lugar al surgimiento de la obligación tributaria de pago, constituyendo, pues, una excepción a los efectos normales derivados de la realización de aquel. El método jurídico para que esto ocurra ha sido explicitado por Sainz De Bujanda (1963) con la concurrencia de dos normas que poseen sentido contrapuesto. La primera define el hecho imponible y le asocia el efecto de nacimiento de la obligación tributaria; la segunda, constituida por la norma de exención, enerva los efectos de la anterior, disponiendo que no se desarrollen respecto a determinados sujetos que realicen el hecho imponible (las llamadas exenciones subjetivas) o impidiendo que se apliquen a determinados supuestos incluidos en éste que la propia norma exoneradora precisa (exenciones objetivas). Desde esta perspectiva vemos cómo el hecho imponible del tributo se ve despojado de su contenido propio por una norma posterior que impide el nacimiento y realización de la obligación tributaria en estos casos concretos. La exención constituye, así, el envés del tributo, es decir, normas de excepción que se oponen a la generalidad enmarcada en la norma tributaria quitándole eficacia mediante la sustracción de su ámbito de aplicación respecto de supuestos o personas determinadas. Esta sustracción puede devenir siguiendo una política de naturaleza tributaria, es decir, teniendo en cuenta los principios rectores de la misma o persiguiendo una finalidad de naturaleza extrafiscal. Pont Clemente (1986), con buen criterio, establece en este sentido que "las exenciones que hallan su fundamento en el Principio de Capacidad Contributiva, no debieran ser consideradas normas excepcionales... sino normas especiales" (p. 21). Existen autores que, admitiendo y aceptando el carácter excepcional de 
las normas de exención, no coinciden totalmente con esta postura en cuanto a la clasificación dada por la generalidad de la doctrina clásica y consideran la exención tributaria como:

a. la especie de un género más amplio, el de los Beneficios Tributarios. El alcance de este tipo de normas puede llegar hasta la total anulación del efecto del hecho imponible (exención total o propiamente dicha) o bien reconducirse a un aligeramiento de la carga tributaria (bonificaciones, deducciones, etc.). De esta manera, las únicas exenciones que existirán serían las extrafiscales, mientras que si las razones en que se funda el hecho excluido se basan en el principio de Capacidad Contributiva, se trataría de un supuesto de no sujeción (Lallane Fama, 1996: 19); y (Lallane Fama, 1996, p. 19)

b. tanto las exenciones como los beneficios tributarios son hipótesis neutralizantes que acompañan a la norma jurídica reguladora del hecho imponible sujeto a tributación, constituyen límites al principio de Generalidad y sus fundamentos deben buscarse en la política fiscal y no en el derecho tributario, pero encuentran en sí marcadas diferencias tales como: en la exención la desconexión entre hipótesis y mandato es total (García Vizcaino, 2017), por eso puede decirse que el sujeto pasivo exento no es un auténtico sujeto pasivo tributario, pero tampoco constituye "un evasor legal" del tributo; en cambio, en los otros casos, la desconexión entre hipótesis y mandamiento no es total sino parcial, siendo disímiles los nombres que signan las distintas leyes tributarias a estos beneficios, entre otros, franquicias, desgravaciones, amortizaciones aceleradas, etc. (Villegas, 2015).

\section{Como Situación Objetiva configuradora del Tributo}

Este enfoque doctrinal hace hincapié en que las normas de exención no constituyen el envés del tributo, ni puede establecerse tampoco que se trate de normas excepcionales que atentan contra el principio de generalidad y los criterios de Justicia Tributaria, sino todo lo contrario, estas normas complementan y delimitan desde dentro el hecho imponible del tributo, constituyendo un todo orgánico con la imposición, y obedeciendo a valoraciones de orden funcional, esto es, internas a la mecánica del hecho imponible. En opinión de González García "son iguales de comunes las normas de imposición como las de exención, cada una en su caso" García (1997, p. 61), la realización del supuesto de exención implica la realización del hecho imponible, pero en este caso, "aún verificándose la subsunción de un hecho por el hecho imponible, no surgen los efectos propios de tal subsunción, esto es, el nacimiento de las situaciones subjetivas tributarias activas y pasivas correspondientes, sino que esos efectos quedan enervados por la convergencia, 
junto al hecho susceptible de ser encajado dentro del hecho imponible, del supuesto de exención. En una palabra, la realización del presupuesto de hecho del tributo y del supuesto de exención es normalmente simultánea, pero la realización del segundo tiene como efecto principal paralizar los efectos que se derivan de la realización del primero" (González García, 1997: 63).

Siguiendo esta postura, la exención no hace más que restablecer la situación de equilibrio existente con anterioridad a la realización del hecho imponible, situación que debe basarse en el respeto de los principios tributarios, en especial, el de capacidad contributiva. Esto resulta de más fácil comprensión a medida que la capacidad contributiva va dejando de considerarse como cualidad objetiva del presupuesto de hecho del tributo para ir entendiéndose como cualidad del sujeto tributario, a la cual debe acomodarse la carga en que el tributo consiste, o incluso, no ya cada uno de los tributos sino el conjunto de los mismos que sobre él recaen (Rezzoagli, 2006).

Así, es el propio principio de capacidad contributiva el que aparece como legitimador de la exención a través de la corrección que esta última realiza al hecho imponible cada vez que dicho principio no se encuentra fielmente reflejado en el mismo. Afirmación ésta que puede ampliarse a cualquier tipo de minoraciones de carácter estructural (reducción, deducción, mínimo exento), es decir, se persigue a través de éstas la defensa y legitimación del principio de Capacidad Contributiva en las distintas etapas del tributo ya sea en forma total o parcial (hecho imponible, base, cuota).

Las normas de exención no tienen por objeto beneficiar o penalizar los supuestos que contemplan, son el producto de consideraciones legislativas de Igualdad, sin contradecir el principio de Generalidad, ya que el deber de contribuir no supone que "todos", de forma indiscriminada, estén obligados a pagar tributos, y las exenciones se realizan como una modalidad integrante de ese deber de contribuir. Por tanto, y teniendo en cuenta los principios constitucionales de justicia tributaria, podemos comprobar que las exenciones se manifiestan como normas ordinarias que redefinen el hecho imponible sujeto a tributación respetando, como modalidad integrante del mismo, el principio de Generalidad por el cual se establece el deber de contribuir a los gastos públicos (Rezzoagli, 2006).

Pese a este inicial pronunciamiento, es innegable que la multiplicación de las necesidades públicas y de las funciones encomendadas a los poderes públicos, supuso la necesidad de acudir a nuevos recursos o a nuevas formas de utilización de aquellos tradicionalmente utilizados o integrantes de la Hacienda Pública (Rezzoagli, 2013). En cualquier caso, es una realidad incuestionable que, como consecuencia de la Hacienda Funcional, se ha generalizado en los Estados contemporáneos el fenómeno de utilización del tributo con fines extrafiscales y, de todos los aspectos del fenómeno de tributación en donde más se ha notado su utilización 
es, sin lugar a equívocos, en las exenciones y demás minoraciones tributarias como la reducción o la deducción. La cuestión estriba en saber cuándo estamos ante una exención tributaria propiamente dicha y cuándo nos encontramos con medidas incentivadoras o de promoción que suelen llamarse exenciones extrafiscales o beneficios tributarios (Rezzoagli, 2006).

La diferencia fundamental radica en el fin directo o inmediato que cada una de estas normas posea, nadie discute hoy en día que los objetivos fiscales y extrafiscales van de la mano y se pueden encontrar en cualquier tributo o minoración, pero es, justamente, esa finalidad inmediata que se pretenda lograr lo que las diferencia sustancialmente. En las falsas minoraciones el objetivo directo es favorecer determinadas conductas o actividades perseguidas por el legislador, mientras que en las minoraciones tributarias, particularmente en la exención, lo que se pretende es salvaguardar los principios de Justicia Tributaria y evitar que tributen personas que por sus condiciones o actividades no tendrían que hacerlo por una cuestión exclusivamente de Capacidad Contributiva. Puede suceder, y de hecho sucede, que pese a esta finalidad, se logre algún objetivo extrafiscal, debido a esa íntima conexión a la que hicimos referencia, pero no fue este último el que motivó al legislador a redefinir el presupuesto de hecho del tributo, sino el criterio de justicia tributaria.

\section{Beneficios Tributarios o Incentivos Fiscales}

Siendo estas medidas o instrumentos muy numerosos dentro del ordenamiento, son asimismo los que resultan de más difícil justificación (Rezzoagli, 2013). Al igual que los tributos con fines no fiscales, tampoco los beneficios tributarios han encontrado un fácil acomodo desde la perspectiva jurídica (Falcón y Tella, 1989, p. 707), aunque dada su incesante extensión, así como la necesidad que desde una óptica económica se les atribuye, no han sido pocos los esfuerzos tendientes a conciliar su presencia en el ordenamiento con unos postulados de justicia que resultan irrenunciables cuando se aborda el fenómeno tributario como fenómeno jurídico, debiendo ordenarse, por tanto, a la consecución de la justicia (Lozano Serrano, 1988, p. 30).

La exoneración o desgravación del tributo solo puede ser justa en cuanto no suponga una vulneración de los principios constitucionales. La validez de este juicio no presenta, en principio, ningún problema cuando aquel instituto se desenvuelve dentro del marco que le es propio: el medio para recaudar ingresos y expresión del deber constitucional de contribuir al sostenimiento de los gastos públicos. Sin embargo, esa valoración inicial aparece puesta en cuestión cuando el tributo se presenta como figura ambivalente (o polivalente) en función de los distintos objetivos que le asigna el propio ordenamiento jurídico. 
Toda norma que reconoce un beneficio fiscal actúa, en principio, contra el principio contributivo (capacidad económica), ya que dicho principio no es solo el criterio jurídico constitucional sobre el cual se estructuran las normas que diseñan las distintas obligaciones contributivas, sino también el criterio rector del deber de contribuir en cuanto mecanismo genérico abstracto, sobre la base que se ordena el reparto de las cargas pública. En este sentido, toda norma que exima o reduzca la carga de la obligación en que se concreta el deber de contribuir, excepto cuando lo haga atendiendo a consideraciones de capacidad económica, atentará contra aquel principio en la medida en que rompa el equilibrio en la distribución del sacrificio tributario. A pesar de lo mencionado con anterioridad, las normas que regulan los beneficios tributarios no se establecen contra aquel interés, sino más bien con independencia del mismo o subordinándolo, por regla general, a otro interés distinto que se considera igualmente digno de protección y más elevado, todo ello partiendo de la ambivalencia a que nos hemos referido anteriormente.

"En estos casos -señala Soler Roch (1983)-, el elemento finalista de los beneficios tributarios aparece elevado a la categoría de sustancial; la instrumentalidad de la norma tributaria al servicio de la política económica es lo que cuenta y, desde esta perspectiva cualquier análisis que prescinda de ese elemento teleológico aparece juzgado como erróneo e insuficiente" (p. 37). En este mismo sentido Sainz de Bujanda (1963) ha observado que:

con ese enfoque pudiera creerse que el planteamiento jurídico del
tema no puede, bajo ningún aspecto, ser sustancial. Esta calificación
habría tan solo de corresponder a aquel tipo de planteamiento que
conduzca al análisis del problema dentro del campo en que quieran
indagarse las posibilidades operativas de la exención por vía del estí-
mulo. Lo sustancial, en suma, sería lo social o lo económico, quedando
lo jurídico reducido a un papel puramente formal o instrumental,
al servicio de los estímulos que, con valoraciones extrajurídicas, se
reputen apetecibles (p. 389)

Es en este punto donde surge la divergencia de opiniones en el seno de la doctrina jurídico financiera, cuando se plantea si es lícito que el mecanismo tributario se utilice con base a criterios a los que aparece subordinado, no solo el interés en la realización del crédito tributario, sino, sobre todo, los principios de justicia bajo los cuales se ordena constitucionalmente el deber de contribuir. Es conocida la postura mantenida por Sainz de Bujanda (1963) en torno al problema de la legitimidad constitucional de los beneficios tributarios, estableciendo que no es posible subordinar o destruir la justicia tributaria en aras de otras posibles manifestaciones de justicia que puedan operar en el seno del ordenamiento jurídico,

es claro que por esa vía serán los restantes sectores sociales los que paguen, con una aportación comparativamente mayor, el régimen de 
exoneración creado en favor de los especialmente favorecidos por las exenciones. Y la injusticia que así se produzca no podrá estar nunca justificada por otro tipo de afanes: Jamás la injusticia puede servir a la justicia. (Sainz de Bujanda 1963, p. 389)

Los beneficios o Incentivos Fiscales, en cuanto suponen una exoneración total o parcial de la carga impositiva para determinados contribuyentes, originan una disminución de los ingresos por este concepto al Erario Público. Por lo tanto, económicamente, son equiparables a la realización de un gasto directo.

Velarde Aramayo (1997) identifica los beneficios tributarios con el gasto fiscal o tributario, dándoles un sentido complejo pues, por un lado, poseen naturaleza tributaria al ser integrantes del ordenamiento y crearse mediante ley (tal como lo declara el artículo 133.3 de la Constitución Española), pero son, por otro lado, fruto del accionar político promocional ya que sus fines son económico - sociales, es decir, se crean exprofeso para potenciar el desarrollo de ciertas actividades, manteniendo total independencia del principio de capacidad contributiva.

En similar sentido, aunque de carácter más atenuado, Herrera Molina (1990) establece que, no parece contrario al deber de contribuir que tributen en menor grado o que dejen de hacerlo aquellos entes cuya potencia económica satisface directamente intereses generales. La capacidad económica de estos entes "exentos" se encuentra cualificada por su afectación al interés general. Un sistema tributario justo debe someter esa riqueza a menos gravamen, sin que por ello se quiebre el deber de contribuir.

De este origen del gasto como un no ingreso, el término beneficios fiscales representaría lo que la doctrina ha llamado Gasto Fiscal o Gasto Tributario, el cual manifiesta una "naturaleza híbrida" (Fuentes Quintana, prólogo de Lagares Calvo, 1974, p. 8), ya que por un lado se encuentra situado en la parte de Ingresos presupuestarios, a los cuales afecta disminuyéndolos (se resta de los mismos), y por otro lado, constituye un gasto a favor de los sujetos beneficiados por la normativa promocional (efectos externalizables directos e indirectos), aunque sea un gasto sin pago.

El gasto tributario (término presupuestario para referirse a los beneficios fiscales), para cierto sector doctrinal, no puede considerarse como Gasto Público en el sentido estricto de la palabra. La realización del gasto público presupone una erogación de caudales públicos previamente ingresados al Tesoro, lo cual no sucede en el caso del gasto fiscal.

En efecto, la dualidad ingreso - gasto, que normalmente tiene lugar en la actividad financiera, carece de operatividad en los gastos fiscales, ya que éstos se presentan bajo la fórmula de un "no ingreso" (González Sánchez, 1982, p. 681), por eso se lo considera de naturaleza híbrida, tal como mencionamos anteriormente. 
Creemos adecuado referirnos al mismo como el gasto generado como consecuencia de un no ingreso de riquezas al Tesoro, provocado por la consecución de una política económica o social llevada a cabo por distintas técnicas impositivas de desgravación. De esta manera el término Gasto Fiscal o Tributario se vería reducido en la legislación impositiva a la expresión Beneficios Tributarios (que representa las minoraciones de carácter extrafiscal), lo que consideramos el criterio correcto a seguir.

El concepto de Gasto Tributario tiene importantes implicaciones en el proceso presupuestario ya que, si aquellos son esencialmente equivalentes a los Gastos Directos canalizados a través del sistema tributario, habrá que entender congruentemente, que resulta imprescindible conocer la magnitud del gasto que se ha realizado por la vía del no ingreso. El Presupuesto o Informe de Gastos Tributarios o Fiscales desempeña una función vital en la ordenación presupuestaria, al poner de manifiesto las cantidades que no se recaudan como consecuencia de la creación y utilización de estos beneficios tributarios ${ }^{5}$, en el mismo documento se establece una cifra total de los beneficios que afectan a los tributos del Estado y se los identifica de forma concreta uno por uno (todos aquellos contenidos en la normativa del propio tributo o individualmente creados a través de leyes de promocionales de distinto tenor y alcance).

En mayoría de los países americanos, no existe mención constitucional alguna sobre los beneficios tributarios o el Gasto Tributario, lo cual resulta interesante pues la utilización de esta figura por el legislador constituye práctica habitual. Si repasamos las últimas legislaciones fiscales en los distintos países del continente americano, las mismas se encuentran plagadas de estímulos o beneficios fiscales a determinadas actividades o condiciones que realicen o cumplan empresas y particulares.

Este elemento así constituido, puede fácilmente desvirtuarse y, por lo tanto, representar un caldo idóneo para el desarrollo de actividades corruptas, debido a que pueden constituirse en verdaderos favores legislativos a determinadas em-

5 Observa Albiñana García - Quintana que “... solo las exenciones - totales o parciales - que se conceden y liquidan como instrumento de política socio - económica deben integrarse en el Presupuesto de Gastos Fiscales. Ni las no sujeciones, ni las exenciones técnicas, deben lucir en la recaudación (bruta o íntegra) del correspondiente concepto tributario. Las mismas desgravaciones cuando sean meras devoluciones de tributos liquidados y recaudados deben ser soportadas presupuestariamente por la respectiva recaudación. Caso distinto es el de la desgravación que opera como una exención ex post porque el procedimiento o técnica que se aplique (supuesto de exención con progresividad, por ejemplo) exigen su previo gravamen para practicar, después, la desgravación que constituye la exención tributaria establecida". Prosigue el autor diciendo que "tampoco debe incluirse entre exenciones o bonificaciones tributarias, aquellas medidas o disposiciones que responden al cuadro normal del tributo de que se trate. Me refiero, por ejemplo, a las de reconocimiento de circunstancias familiares en un impuesto personal sobre la renta de las personas físicas. La justicia social recaba de determinados impuestos ciertas exoneraciones o bonificaciones que no son verdaderas exenciones del gravamen, sino traducción normativa de la concepción vigente que del tributo se tenga". (Albiñana García - Quintana, 1979,p. 49; En similar sentido: Braña Pino, 1981: 81). 
presas o factores de poder, puesto que a los grandes capitales, para no generar sospecha ni condena social, prefieren dejar de pagar lo que deben a recibir subsidios fraudulentos, puesto que en definitiva la ventaja económica obtenida es la misma, y, por supuesto, estos privilegios infundados generan un efecto regresivo en el sistema tributario y una mayor tributación del resto de los sujetos, que, en definitiva, deben solventar, con mayor gravamen impositivo, los perdones concedidos y así mantener el contrabalanceo del sistema.

Para Clemens Fuest y Nadine Riedel (2009) los gastos tributarios son ampliamente criticados como instrumentos de política económica por la falta de transparencia y porque son difíciles de controlar. Se cree que son vulnerables a la presión ejercida por grupos que poseen "intereses especiales" y prácticas incluso corruptas. Por lo tanto, las estrategias para el control de los gastos tributarios o fiscales pueden ser un elemento importante en una estrategia más amplia de mejorar la movilización de los ingresos en los países en desarrollo.

Stanley Surrey (1973), luego de analizar estos elementos y su vinculación con el entramado de corrupción pública, se manifestaba en términos tajantes por la desaparición de los mismos del sistema fiscal y su sustitución por los gastos directos, en su caso, sobre la base de la constatación de los múltiples inconvenientes que esta figura presenta y la crítica de sus pretendidas ventajas.

\section{Desarrollo doctrinario y jurisprudencial de la cláusula de progreso}

Una vez realizado el análisis de los instrumentos minorativos, principales herramientas para la realización y efectivización del poder de eximir que proclama la Constitución Nacional en su artículo 75 inciso 18, es que podemos ahora adentrarnos al análisis del mismo.

La Corte Suprema de Justicia de la Nación en numerosas ocasiones recurrió a la calificación de instrumentos de Gobierno, en interpretación y justificación del actual artículo 75 inciso 18 constitucional. Sin pretender agotar la lista de supuestos -ni dentro de ellos todos los casos donde así fueron considerados, se intentará recorrer seguidamente unos pocos de los más relevantes a los fines tributarios y en íntima conexión a la aplicación de beneficios fiscales.

Pues bien, en virtud entonces de dicha cláusula de progreso se concedió al Congreso la facultad de crear minoraciones de cualquier tipo, inclusive las extrafiscales, sin la limitación de que solo afectara a impuestos nacionales, en consecuencia, el Congreso de la Nación estimó conveniente establecer beneficios fiscales de amplitud variable, alcanzando en numerosos casos a los tributos provinciales y municipales. En opinión de Casás, (1996) 
la cláusula de progreso asigna al Estado un rol protagónico para promover las condiciones que faciliten el desarrollo no sólo económico, sino también social, educativo y cultural, y la consecución de tales fines, indudablemente habilita a los poderes públicos para otorgar beneficios y franquicias tributarias temporales, especialmente, a proyectos e inversiones siempre que guarden razonable equivalencia con los capitales aportados y los riesgos asumidos por el sector privado. (p. 183)

La Corte Suprema de Justicia de la Nación desde el año 1897 efectuó una interpretación amplia del entonces artículo 67 inciso 16 (actual 75 inciso 18), considerando que el Congreso puede otorgar exenciones a toda clase de tributos, aún provinciales y municipales, con inclusión de tasas retributivas de servicios y contribuciones de mejoras.

En la primera oportunidad, causa "Ferrocarril Central Argentino c. Provincia de Santa Fe", de 3 de Julio de $1897^{6}$, el Alto Tribunal expresó que "para los fines de gobierno, de política, de reglamentación del comercio interprovincial, o simplemente como medio de estímulo para promover la construcción de un ferrocarril el Congreso cree conveniente acordar el privilegio de la exención del pago de impuestos locales, esta disposición será perfectamente constitucional, porque ella no importará sino el ejercicio de una facultad del Congreso cuyas leyes priman sobre cualquier disposición contraria que pudieran contener las Constituciones o Leyes de provincia. Resolver lo contrario sería reconocer en los gobiernos de provincia la facultad de anular o entorpecer los efectos de la legislación del Congreso, en cuanto ella se dirigiese a los objetos previstos en el inciso diez y seis del artículo sesenta y siete"7. En esta materia la situación fue la siguiente: el constituyente de 1853/60 previó que, para la integración económica del país, era preciso no solo el fomento de la inmigración, sino también la importación de capitales, especialmente para el desarrollo de las vías de comunicación y, entre ellas, las vías férreas.

Mediante la ley del 23 de mayo de 1863 se aprobó el contrato para la construcción del Ferrocarril Central Argentino, declarando en su art. $4^{\mathrm{o}}$ libre de toda contribución o impuesto la propiedad del ferrocarril y sus dependencias, por el término de 40 años, como asimismo libres de gravámenes aduaneros la importación de materiales, útiles y artículos para su construcción y uso exclusivo. En la causa de Fallos: 68:227 se sentó definitivamente la interpretación del art. 67, incs. 16 CN (actualmente inc. 18 del art. 75) en cuanto a que le confiere competencia amplia al Congreso Nacional para lograr los fines allí trazados.

6 Fallos: 68:227.

7 Fallos: 68:227 (“Ferrocarril Central Argentino c. Provincia de Santa Fe”, de 3 de Julio de 1897). Pueden encontrarse referencias semejantes en Fallos: 104:73 ("Ferrocarril Central Argentino c. Municipalidad de Rosario", de 31 de Marzo de 1906), Fallos: 113:165 ("Municipalidad de Tucumán c. Ferrocarril Central Argentino", de 7 de Junio de 1910), y en Fallos: 185:24 (“Municipalidad de Neuquén c. Ferrocarril Sud”, de 6 de Octubre de 1939). 
Las "exenciones" dictadas beneficiaron en general a empresas de ferrocarriles, aunque posteriormente adquirieron mayor amplitud, comprendiendo, entre otras, a telefónicas y empresas de radiodifusión ${ }^{8}$, hasta llegar a las leyes de promoción industrial en general ${ }^{9}$. De esta manera, en la causa "Compañía Entrerriana de Teléfonos c. Provincia de Entre Ríos", de 23 de abril de 1941, al reiterar su doctrina en una cuestión relativa a instalaciones radioeléctricas de vinculación interprovincial, el Tribunal reafirmó su postura en otorgar concesiones temporales de privilegios con carácter amplio, sosteniendo que

dentro de esta coordinación armónica de intereses entre concedente y concesionario, no es posible concebir la intromisión de otra entidad soberana con facultades impositivas, porque sea por error, por falta de un conocimiento cabal o íntimo de las cosas, o sea por un criterio divergente, establecer impuestos que rompan el equilibrio existente y hagan imposible la continuación de los servicios ${ }^{10}$.

A este respecto señala Luqui, (1989)

que al conservar las provincias todos los poderes que no han delegado al Gobierno Nacional, va de suyo que retienen aquellos poderes que le permitan otorgar las referidas concesiones de privilegios y otorgar recompensas de estímulo dentro de sus jurisdicciones. En cambio, siendo los poderes del Congreso expresos, limitados y definidos, fue necesario consignar esos medios, que así, aún cuando se proyecten en materias o territorio provincial, serán prevalecientes a los poderes conservados a las provincias, especialmente en punto a exenciones tributarias dictadas por el Congreso sobre tributos provinciales. Por ser de excepción esa atribución es que las concesiones de privilegio deben ser temporales, de otra manera existiría una contradicción entre los poderes reservados y los delegados. (p. 132)

Por su parte Giuliani Fonrouge (1941) señala acertadamente que

la situación de la República Argentina al sancionarse la Constitución de 1853 era muy distinta de la actual. En aquella época todavía no se habían apagado las pasiones despertadas por las luchas civiles, el localismo era un peligro latente, la riqueza pública y privada estaba en formación, el país entero se debatía en la antinomia de civilización o barbarie. De ahí que lo más urgente era poblar el país, fomentar sus

Fallos: 188:247 (“Roca Hnos. y Cía. Ltda. S.A. c. Provincia de Santa Fe”, de 13 de noviembre de 1940), Fallos: 189:272 (“Compañía Entrerriana de Teléfonos S.A. v. Provincia de Ente Ríos”, de 3 de Abril de 1941).

9 Fallos: 314:1088 (“Carlos Pascolini S.A. c. Estado Nacional”, de 24 de septiembre de 1991). 
industrias, atraer capitales, desarrollar el comercio y la navegación. Hoy en día, dichas empresas no tienen el mismo carácter aleatorio, de ello se sigue que en los tiempos que corren no es posible, forzando los textos constitucionales, extender genéricamente y en forma absoluta e indiscriminada, los alcances del artículo 75 inciso 18 de la Constitución Nacional, comprendiendo en sus disposiciones la dispensa de gravámenes provinciales o municipales, si bien en la etapa de formación nacional, el estado de la necesidad justificaba tal interpretación de la norma constitucional. (p. 215)

En una posición similar se encuentra Spisso (2000), quien luego de analizar ciertos fallos de la Corte asegura que "aquí ya no se trata de promover ciertas actividades mediante concesión temporal de privilegios o recompensas de estímulo, sino sencillamente de ampliar las facultades de la Nación, cercenando la de las provincias, todo ello con evidente menosprecio de la Constitución Nacional” (p. 79).

La cláusula de progreso si bien debe ubicársela en el contexto en que fue sancionada ha sido interpretada por nuestra Corte Suprema de tal forma que se ha mantenido vigente hasta nuestros días como justificación de la recepción extrafiscal a través de todo tipo de minoraciones frente al principio de Igualdad (Linares, 2002, p. 177). La facultad que le corresponde al Congreso de la Nación según esta disposición debe ser estrictamente temporal para la SCJN ${ }^{11}$, pues de otra forma contravendría los poderes reservados por las provincias no otorgados a la Nación.

No obstante la amplitud con que fue concebida la doctrina a favor de las facultades de la Nación, para establecer "dispensas" de tributos, la Corte, atenuando su postura admitió que la facultad del Congreso no debía entenderse con alcance discriminado y absoluto ${ }^{12}$, sino que, por el contrario, atento a su carácter excepcional y temporal, es necesario que se la juzgue en virtud de su naturaleza desarrollada por quien la invoca y de la índole del tributo, so pena de cercenar, de otro modo, las facultades impositivas de las provincias (Lalanne Fama, 2002), que estas deben ejercer en su ámbito propio, en tanto no hayan sido delegadas al Gobierno Nacional.

La importancia que tiene la atenuación de la postura del Alto Tribunal, se refleja en su preocupación por expresar los motivos que justifican el trato impositivo desigual, aún ante situaciones de similar capacidad contributiva, y no se

11 Fallos: 68: 227 ("Ferrocarril Central Argentino c. Provincia de Santa Fe”, de 3 de Julio de 1897), Fallos 113: 165 (“Municipalidad de Tucumán c. Ferrocarril Central Argentino", de 7 de Junio de 1910), Fallos: 185: 24 (“Municipalidad de Neuquén c. Ferrocarril Sud”, de 6 de Octubre de 1939). En definitiva, como señala Luqui (1993), "el poder del Congreso de la Nación de crear exenciones tributarias en todo el territorio del país, tiene la limitación en que, tratándose de tributos provinciales y municipales, estas tengan un término. Además, como todo poder implícito, la exención debe guardar una relación de causa efecto con alguno de los objetivos enumerados en el inciso 16 (actual artículo 75 inciso $18 \mathrm{CNA}) "$ (p. 222).

12 Fallos: 258: 208 (“S.A. Compañía Frigorífica Swift de la Plata v. Comisión de Fomento de Villa Gobernador Galves", de 22 de Abril de 1964). 
limita a afirmar solamente la existencia de la "cláusula de progreso". Por consiguiente, la justificación del trato impositivo diferencial deviene del reconocimiento de que la facultad de establecer "dispensas" no es absoluta, y debe encontrar fundamento en el bien público ${ }^{13}$ y por otras normas constitucionales igualmente dignas de desarrollo ${ }^{14}$.

Ahora bien, haciendo nuestra la opinión del maestro español González García (2002), en los beneficios tributarios conviene partir de la observación de que existen intereses dignos de protección fuera del ámbito del principio de capacidad contributiva, de donde algunos deducen que la justicia tributaria no puede agotarse en el reparto del coste de los servicios públicos, sino que debería abarcar también el conjunto de minoraciones tributarias dirigidas a favorecer el desarrollo económico o a incrementar el bienestar social, a partir de la elemental consideración que las aportaciones de los ciudadanos al bien común pueden seguir diversos caminos.

En la medida en que esas aportaciones ahorren dinero al Estado, se hacen acreedoras de un trato fiscal favorable, pues aunque supongan un gasto para el Estado, deben considerarse una especie de "mal menor necesario" para obtener bienes mayores. Sin perjuicio, naturalmente, de que la valoración de las actividades que afectan al interés público corresponde al poder político (González García, 2002). La circunstancia de que el Congreso haya puesto en vigencia determinada política respecto de alguna de las materias del artículo 75 inciso 18 de la Constitución Argentina, no elimina, sin más, todas las facultades legislativas de las provincias susceptibles de guardar relación con esa misma materia.

En palabras de Spisso, (2000)

"sólo en situaciones en que aparezca suficientemente demostrado que la ley local frustre, entorpezca o impida la realización de la política nacional, sancionada en ejercicio de poderes atribuidos a la Nación por la Constitución, se podrán invalidar las normas impositivas provinciales o municipales que se hallan en pugna con aquella". (p. 186)

El "trato diferencial" dado por el Congreso de la Nación a través de beneficios tributarios requiere de una especial justificación (García Etchegoyen, 2004), por lo que la Corte y la doctrina hacen referencia al criterio de Razonabilidad al momento de evaluar un beneficio tributario frente al principio formal de Igualdad, y consideran inconstitucional la concesión de beneficios que no encuentre sustento en un fundamento razonable (Valdez Costa, 1992; Villegas, 2002; García Belsunce, 1982; Casás, 1992), en una ponderación de los bienes jurídicos en juego (Spisso, 1994), es decir, que no resulten arbitrarios y discrecionales, vulnerando así el principio de Igualdad (Rosembug, 1989).

Fallos: 237: 239 (“Empresa Vesta de Construcciones v. Municipalidad de Santiago del Estero”, de 13 de Marzo de 1957).

Fallos: 185: 24 (“Municipalidad de Neuquén c. Ferrocarril Sud”, de 6 de Octubre de 1939). 
Por último, en este punto, sin hacer un pormenorizado análisis constitucional de la existencia o inexistencia de una "posible" potestad autónoma de eximir, como otro poder o facultad absolutamente independiente al de exigir contribuciones, creemos que desde el exclusivo análisis estructural del tributo y del poder tributario la respuesta debe ser negativa. En este sentido es clara la posición del español Palao Taboada (1982) cuando manifestó que

\begin{abstract}
el supuesto derecho a la exención o bonificación (para períodos futuros, aún y cuando lo determine la propia ley exoneradora) no forma parte del patrimonio (de los sujetos beneficiados) sencillamente porque no existe (como derecho autónomo), ya que, utilizando la terminología del Tribunal Constitucional, es simplemente un elemento de la relación jurídica obligacional; es decir, la norma de exención no crea ninguna situación jurídica a favor de los contribuyentes, sino que se integra en las normas delimitadoras del presupuesto de hecho del impuesto. (p. 167)
\end{abstract}

\title{
Respecto a su tratamiento y cálculo presupuestario
}

Llegados a este punto, y realizada la crítica a la interpretación dominante de la Cláusula de Progreso, haremos una muy breve referencia a los beneficios tributarios existentes respecto de su cálculo presupuestario, o mejor dicho, a las necesidades que deben atenderse en el mismo.

Pretendiendo creer en la intención loable del legislador, o excepcionalmente en el Presidente al redactar decretos de necesidad y urgencia, la pregunta puede plantearse de la siguiente manera: ¿Cómo saber que los beneficios o estímulos fiscales introducidos fueron necesidades de Gasto Público que el Estado debía cubrir para el desarrollo del país?; ¿Quién los controla y evalúa?; ¿Existe un seguimiento respecto a la efectividad del "gasto" como sucede en el sistema financiero?

Estos planteamientos resultan de fundamental trascendencia a la hora de crear y desarrollar beneficios tributarios, puesto que en definitiva son verdadero Gasto Público, aunque formalmente se incluyan en el Presupuesto de Ingresos bajo signo negativo, puesto que son necesidades sociales y económicas que el Estado debe afrontar, ya sea a través de la entrega de fondos públicos anteriormente ingresados al Erario o, como en este caso, calculando la suma de dinero del Gasto a cubrir y, en vez de recaudar para gastar, contemplarla como un no ingreso y así potenciar el principio de solidaridad, haciendo que los ciudadanos, a través de sus potencias económicas de manera directa, cumplan la tarea que, de otra forma, el Estado tendría que realizar de todas maneras (Rezzoagli, 2013).

Para esto se requiere de una verdadera planeación y programación presupuestaria, donde se pongan de manifiesto las necesidades a cubrir a través de un Informe o Presupuesto de Gastos Tributarios (Rezzoagli, 2006), desde mediados 
de los años 90s en Argentina contamos con dicho informe, sin embargo, la articulación de los montos de regímenes promocionales o exoneraciones fiscales de carácter extrafiscal, se articulan exclusivamente en el cálculo de los ingresos bajo signo negativo, debido a que es una disminución calculada de los mismos.

Ahora bien, saber que se hace con ese dinero no ingresado y como afecta a los egresos es lo que causa dolores de cabeza: dicho presupuesto o informe de gasto tributario debe tener relación directa con el cálculo de los Gastos Públicos (extrayendo los montos de las partidas y rubros pertinentes) y así poder luego trasladarse al cálculo de los ingresos bajo signo negativo. Así pues, sin esta planeación, no sabríamos si lo que estamos dejando de recaudar como consecuencia de la creación y utilización de beneficios tributarios se dirige a finalidades de primer orden o no, porque puede ocurrir que si no realizamos este proceso adecuado de planeación, estemos utilizando verdadero Gasto Público en el desarrollo de necesidades que no son prioritarias o importantes, en principio, y hasta podemos llegar a concluir que ni siquiera pueden llegar a ser verdaderas necesidades públicas, alterando e incumpliendo el fin primordial de la recaudación tributaria que consiste en que posea destino de gasto público.

Lamentablemente debemos reconocer que estas figuras, por su escasa publicidad y conocimiento, constituyen elementos idóneos para el desvío de fondos públicos, entendidos desde su aspecto material como un no ingreso calculado (formalmente no serían gasto público debido a que no hay entrada y salida de recursos a la Tesorería), y por lo tanto, se erigen como el caldo de cultivo principal para la corrupción del siglo XXI. Al solo vincularse con los cálculos de los posibles ingresos a recaudar y afectarlos negativamente, es decir, restarlos, se tiene un conocimiento cabal de su cuantía y de lo que implica y como afecta a los ingresos calculados, sin embargo, no tienen vinculación formal o material con el presupuesto de egresos, por lo que no sabemos a qué finalidad de gasto público se cualifica presupuestariamente, tampoco disminuyen correlativamente egresos e ingresos, solo afecta a los ingresos, por lo que materialmente no hacen otra cosa más que aumentar el déficit presupuestario, o lisa y llanamente disminuyen posibles recursos que deberían ir al gasto público sin indicar a donde van y porque dentro de una planeación presupuestaria que resulta funcional a su ocultamiento.

Al no tener vinculación formal o material con los egresos, y por lo tanto no articularse dentro del sistema financiero, no existe posibilidad alguna de control interno o externo, previo, concomitante o a posteriori, ni de evaluar el dinero del Estado en atención de las finalidades perseguidas. Un verdadero agujero negro si se me permite la expresión dentro del universo presupuestario, que llega a afectar nada más ni nada menos que un $20 \%$ en promedio de los ingresos calculados por año en nuestro país.

Ahora bien, volviendo al federalismo, esta potestad tributaria cualificada en la eximición de obligación material de pago total o parcial (sea que se estructure 
en el hecho imponible o la base imponible del tributo afectado), necesariamente genera un desfasaje presupuestario y financiero en las provincias afectadas, pues calculaban con recaudar los montos dinerarios en ejercicio de sus facultades propias impositivas, a las actividades y sujetos comprendidos dentro de su ámbito de vinculación fiscal, pero una exoneración nacional, acción del Congreso de apoderamiento del poder tributario subnacional cualificado a través de normas exonerativas, le impiden a las provincias recaudar lo previsto, lo calculado, con un desfasaje importante en la consecución de sus planes funcionales y financieros.

Una situación de esta envergadura requiere mínimamente de una intervención financiera del Gobierno Nacional para compensar la pérdida de recursos propios y legítimos privados a las provincias afectadas, sin embargo, hasta la fecha, ni siquiera existe esa compensación dineraria que, en pos del cumplimiento de fines "superiores" que el gobierno nacional puede realizar en todo el territorio del país. No cabe duda de que por lo menos se debería entregar desde un ámbito de gobierno a otro, el importe calculado de recaudación que no afrontan los sujetos cualificados por estos regímenes excepcionales y temporales perseguidos.

\section{Conclusiones}

Lo que debemos entender aquí es que el derecho tributario nace de una obligación sustantiva de contribuir a los gastos públicos (fin necesario y primordial de los impuestos), articulada por un poder tributario y unos criterios de vinculación. Dicha obligación puede ser atenuada en todo o en parte a través de exenciones, deducciones, reducciones y demás elementos minorativos, por cuestiones de capacidad contributiva, por cuestiones técnicas (doble imposición) y, lo que acapara nuestra atención, consideraciones extrafiscales, ya que junto con la capacidad contributiva existen muchos otros principios constitucionales dignos de desarrollo desde el ámbito fiscal, tales como la vivienda digna, el pleno empleo, el tener y conservar un ambiente sano, etc. Éstos encuentran en los regímenes promocionales un vehículo idóneo para el cumplimiento de la Igualdad Material y el desarrollo de fines que exceden al ámbito de la justa imposición ${ }^{15}$, puesto que tratar igual a los iguales

15 Si bien la extrafiscalidad puede desarrollarse en materia tributaria tanto en forma directamente proporcional al fin perseguido (beneficios tributarios - regímenes promocionales) e inversamente proporcional a la finalidad deseada (impuestos extrafiscales que persiguen disuadir conductas), respecto a éste último ámbito nuestra opinión es desfavorable.

Un tributo extrafiscal no es lo mismo un tributo con fines extrafiscales; tributos con fines extrafiscales lo son todos, en mayor o menor medida, porque todo tributo entraña el paso de la riqueza del bolsillo del contribuyente al tesoro público y ese paso siempre produce algún efecto económico por sí mismo de forma dirigida o espontáneamente. Todo tributo por el hecho de serlo tiene algún efecto económico distinto del puramente recaudatorio pero no es ese un problema de justicia tributaria; el problema real son los tributos con fines extrafiscales preponderantes, primordiales, que desplazan al fin recaudatorio, es decir, que lo que buscan no es recaudar, y el hecho imponible, necesariamente entonces, no refleja parámetros de riqueza, así puede mencionarse, como ejemplo, evitar la 
en iguales circunstancias muchas veces se torna injusto si nuestro punto de mira es exclusivamente recaudatorio. Pensemos en aquellos sujetos que invierten en maquinarias ecológicas, quienes contratan personas con capacidades diferentes o con graves problemas físicos, quienes potencian el desarrollo económico y comercial en determinadas zonas de emergencias a primera vista poco rentable, etc., son sujetos que arriesgan su capital en la consecución de fines sociales, queridos por el legislador y amparados en la constitución y leyes ordinarias.

Son situaciones que el Estado de todas maneras debería de afrontar si no lo hacen los particulares a través de su accionar solidario, por lo que el subvencionar actividades o empresas es igual a dejar de recaudar por la consecución de dichos fines que de otra forma hubiese implicado el desplazamiento de fondos, con todo el gasto administrativo y el riesgo que ello conlleva, por lo tanto, los beneficios fiscales implican una complementación del antiguo binomio ingreso - gasto, porque el no "beneficiar" a estos sujetos que cumplen con las finalidades públicas del Estado de manera directa, podría ser equitativo y proporcional, atendiendo al aspecto exclusivamente recaudatorio, pero indudablemente sería injusto, porque la Igualdad no puede interpretarse solo desde su perspectiva formal, sino también material, eliminando las distancias entre los individuos, a través del seguimiento y consecución de otros valores constitucionales para lograr la verdadera paridad de tratamientos.

Ahora bien, si lo que existe en realidad es una obligación que puede ser minorada en todo o en parte por cuestiones de capacidad contributiva, técnicas, o por consideraciones extrafiscales dignas de consecución y desarrollo, dichas minoraciones o mecanismo minorativos, no son más que instrumentos que pertenecen

\footnotetext{
contaminación (las famosas eco tasas), cuyo hecho imponible está dado por parámetros de contaminación y aunque la contaminación sea una acción terrible y perjudicial para todos, lo que necesariamente NO constituye es una manifestación de riqueza de los sujetos que la realizan.

Existe uniformidad mundial al definir al tributo como instrumento para la cobertura del gasto público, y una cosa es que el tributo además de recaudar haga otras cosas, ningún problema, pero es algo muy distinto a que el fin primordial del tributo sea no recaudar, y prescinda de la capacidad económica al gravar situaciones ajenas a la misma. Aunque utilicemos nuestra imaginación y el más agudo razonamiento para brindarles (de algún modo) constitucionalidad, y nos parezcan instrumentos útiles y necesarios, y de hecho puede que lo sean, simplemente no les corresponde este ropaje jurídico debido a que no son verdaderos impuestos y contradicen sus principios informadores; la tarea, entonces, puede pasar por trabajar en estos falsos impuestos para darles el acomodo constitucional adecuado.

Distinto es el caso de impuestos internos a los cigarrillos, ciertas bebidas alcohólicas, tributos altos a la explotación de juegos de azar, entre otros que podríamos mencionar, puesto que el hecho imponible está constituido por manifestaciones específicas de riqueza (compra - venta - distintos tipos de transacciones comerciales) y que implica el desarrollo de capacidad económica en la transacción; aquí entonces el debate puede darse respecto al límite máximo de la imposición, el principio de No Confiscatoriedad.

Si bien en estos tributos pueda legitimarse alícuotas elevadas por supuestas finalidades extrafiscales como el cuidado de la salud o la lucha contra el juego, el fin recaudatorio sigue siendo primordial o principal en los mismos y haciendo mías las opiniones que vertía en clases de doctorado el maestro español Don Eusebio González García en la Universidad de Salamanca, España, si quieren que el fin principal sea realmente disuadir y no recaudar, pongan impuestos al tabaco al $10.000 \%$ de alícuota, entonces verán que en este país ya no fuma nadie, pero si mantienen un consumo suntuoso generalmente inélastico o con baja elasticidad en términos competitivos, el fin primordial siempre será recaudatorio pese a lo que nos quieran decir.
} 
formal y materialmente a la misma, forman parte inherente del poder tributario de imposición, y no pueden desarrollarse sin que la obligación de la que forman parte se manifieste tanto legalmente como realmente a través de la realización, en cada caso, del hecho imponible que produce su devengo (y en las demás etapas configurantes de la obligación tributaria: base imponible, alícuota y cuota).

Si esto es así, y en consideración a la realización de un proyecto de índole nacional en el que en determinadas regiones pueda encontrar obstáculos de desarrollo efectivo ¿cómo justificar que el Congreso de la Nación, que solo puede crear tributos nacionales, tenga injerencia en elementos que forman parte de tributos provinciales o municipales?, A priori, solo puede tener injerencia legislativa en los mecanismos o elementos que forman parte de los tributos que él mismo crea o atiende, es decir, dentro de la órbita de su poder tributario delineado por los criterios de vinculación fiscal. Pero es aquí donde radica la importancia y trascendencia del artículo 75 inciso 18 constitucional, pues al tratarse la facultad de eximir de una forma de manifestación del propio poder tributario de imposición, lo que regula esta posibilidad por parte del Congreso de la Nación de imponer exenciones en pos del desarrollo del país de forma razonable, de manera excepcional y por tiempo limitado, que cuenta con jerarquía constitucional y por lo tanto se enmarca dentro de la doctrina de inmunidad de los instrumentos de gobierno, es la posibilidad de acceder previamente, y por mandato constitucional, al propio poder de imposición de las provincias y municipios y desde allí cualificar (desde el ámbito general a lo particular) exenciones e instrumentos minorativos para estas pautas y parámetros antedichos.

Volvemos a reiterar que no se trata de entender a la concesión de beneficios como un derecho autónomo, resulta estructuralmente imposible que una exención no se articule dentro del marco propio del hecho imponible donde se devenga, y para ello debe tener el Congreso previamente prerrogativas generales en la configuración de los tributos para cualificar dichas situaciones objetivas o subjetivas que neutralizan la obligación principal de pago, puesto que constituyen elementos de la obligación tributaria de la que forman parte, y que, por lo tanto, solo puede crear quien asume, a su vez, dicha obligación en la que está inmerso.

\section{Referencias}

Albiñana, C. (1979). El Presupuesto de Gastos Fiscales. PGP, (1), pp. 45-51.

Alurralde, A. M. (2005). Sinopsis de derecho tributario provincial. Rosario, Argentina: Juris.

Berliri, A. (1971). Principios de derecho tributario: Volumen ll. Traducción y notas por Amorós Rica, N. y González García, E. Madrid: ed. Derecho Financiero.

Bidart, G. J. (2000). Manual de la constitución reformada, tomo II. Buenos Aires: Ediar. 
Bulit, E. (1991). Acerca de la cláusula del desarrollo en la Constitución Nacional. La Información, t. LXIV, pp. 500-515.

Casás, J. O. (1996). El principio constitucional de generalidad en materia tributaria. Revista Iberoamericana de Derecho Tributario (1), pp. 165-186.

Casás, J. 0. (1992). Presión Fiscal e inconstitucionalidad: Las garantías constitucionales ante la presión del conjunto de tributos que recaen sobre el contribuyente. Buenos Aires: Depalma.

Dominguez, A. (2015). El federalismo unitario argentino (1994-2014). Pensar en Derecho (5), pp. 91-103. Recuperado de http//www.derecho.uba.ar/publicaciones/ pensar-en-derecho/revistas/5/el-federalismo-unitario-argentino-1994-2014.pdf

Caparros, E. F. (2000). La corrupción: Aspectos jurídicos y económicos. Salamanca: ed. Ratio Legis.

Fernández, V. R. (2001). Estrategias de desarrollo y transformación estatal. Buscando al estado bajo el capitalismo global. Santa Fe, Argentina: Universidad Nacional del Litoral.

Fernández, V. R. (1999). Descentralización estatal y decisionismo fiscal: enfoque crítico y propuestas a partir de la experiencia argentina: 1960-1990. Santa Fe, Argentina: Universidad Nacional del Litoral.

Fuest, C. \& Riedel, N. (2009). Tax evasion, tax avoidance and tax expenditures in developing countries: A review of the literatura. Oxford University Centre for Business Taxation.

García, H. A. (1982). Temas de derecho tributario. Buenos Aires: ed. Abeledo - Perrot.

García, M. F. (2004). El principio de capacidad contributiva. Evolución dogmática y proyección en el Derecho Argentino. Buenos Aires: ed. Abaco.

Giuliani, C. M. (1941). Delegación de facultades y exención de impuestos provinciales por el congreso. Buenos Aires: Estudios del Centro de Investigación Permanente de Derecho Financiero.

González, E. (1997). Interpretación de las normas tributarias. Pamplona: ed. Aranzadi.

González, E. (1992). La utilización de los instrumentos tributarios para fines de política económica, en Derecho Tributario. Buenos Aires: Asociación Argentina de Derecho Tributario.

González, E. (2002). Relato general de las medidas fiscales para el desarrollo económico. Génova Barcelona: XXI Jornadas Latinoamericanas de derecho tributario.

García, C. (2017). Manual de Derecho Tributario. Buenos Aires: Abeledo Perrot.

Lalanne, G. A. (2002). El sistema tributario como instrumento de desarrollo e incentivación: Hacia una teoría de la justicia en la no imposición. Génova Barcelona: XXI Jornadas Latinoamericanas de derecho tributario.

Linares, J. F. (2002). Razonabilidad de las leyes (El debido proceso como garantía innominada en la Constitución Argentina). Buenos Aires: ed. Astrea. 
Luqui, J. C. (1993). Derecho constitucional tributario. Buenos Aires: ed. Depalma.

Luqui, J. C. (1989), La obligación tributaria, Buenos Aires: ed. Depalma.

Naveira, G. J. (2007), El 'instrumento de gobierno' como concepto jurídico indeterminado en la jurisprudencia de la Corte Suprema argentina. Estudios en homenaje al profesor Pérez de Ayala. pp. 937- 981.

Palao, C. (1982). La disminución retroactiva de bonificaciones fiscales y los decretos leyes en materia tributaria. Crónica Tributaria (43) pp. 163-179.

Pont, J. F (1986). La exención tributaria. Madrid: ed. De Derecho Reunidas.

Rezzoagli, B. A. \& Alurralde, A. M. (2008). Manual de Finanzas Públicas. México: Fondo Editorial Morevallado.

Rezzoagli, L. C. (2006). Beneficios tributarios y derechos adquiridos. México: Cárdenas Velasco Editores.

Rezzoagli, L. (2013). Teoría de la dinámica fiscal contradictoria de los países latinoamericanos en un ámbito determinado por la coexistencia del capitalismo global y la democracia representativa. Revista de la Facultad de Derecho y Ciencias Políticas de la Universidad Pontificia Bolivariana, 43(118), pp. 117-142.

Rosembuj, T. (1989). Elementos de derecho tributario. Barcelona: ed. PPU.

Sainz, F. (1963). Teoría de la exención tributaria. Hacienda y Derecho, vol. III, pp. 456-472.

Spisso, R. (2000). Derecho constitucional tributario. Segunda edición. Buenos Aires: ed. Depalma.

Spisso, R. (1999). El principio de capacidad contributiva. Derechos y garantías del contribuyente desde la perspectiva constitucional. Buenos Aires: El derecho administrativo, diario de jurisprudencia y doctrina.

Surrey, S. S. (1973). Pathway to Tax Reform. The Concept of Tax Expenditure. Cambridge, Massachusetts: Harvard University Press.

Uriburu, G. (2017). El bien común y la doctrina de la inmunidad de los instrumentos de gobierno. El Derecho. Diario de doctrina y jurisprudencia, 14 (148), pp. 1-8.

Valdes, R. (1992). Instrumentos de derecho tributario. Buenos Aires: ed. Depalma.

Villegas, H. (1992). Curso de finanzas, derecho financiero y tributario. Buenos Aires: ed. Depalma.

Villegas, H. (2015). Curso de Finanzas, Derecho Financiero y Tributario. Buenos Aires: Astrea. 
